\title{
Application of Capillary Isotachophoresis in Phenothiazines Determination
}

\author{
Marzanna Kurzawa*, Anna Filipiak-Szok, Aneta Jastrzębska and Edward Szłyk
}

Faculty of Chemistry, Nicolaus Copernicus University, 7 Gagarin str., 87-100 Toruń, Poland

\begin{abstract}
A capillary isotachophoretic method (cITP) using three electrolyte systems for determination of promethazine, thioridazine and chlorpromazine hydrochlorides in pharmaceutical preparations was demonstrated. Proposed systems were characterised by linearity range $5-100 \mathrm{mg} / \mathrm{L}$ with $\mathrm{R}^{2}$ in all cases were higher than 0.999 . The elaborated method was tested on pharmaceutical preparations. The recovery values were from $96.5 \%$ to $101.3 \%$. The proposed isotachophoretic method is simple with acceptable precision and accuracy and can be suitable for routine analysis of studied biological active compounds.
\end{abstract}

Keywords: Capillary isotachophoresis; Chlorpromazine hydrochloride; Promethazine hydrochloride; Thioridazine hydrochloride

\section{Introduction}

The phenothiazine derivatives such as: promethazine, chlorpromazine and thioridazine hydrochlorides are used as psychotropic, neuroleptic, local anesthetics, anti-allergic and antiyomiting drugs [1]. The therapeutic interest in these compounds group justifies research to establish different analytical methods for the determination of these drugs in pharmaceutical preparations and biological samples.

Many methods have been reported for the analysis of these compounds, including spectrophotometric, fluorimetric, electrochemical and chromatographic. Spectrophotometric methods were based on the reaction between phenothiazine derivative and oxidizing agent such as: cerium (IV), potassium dichromate, chloramines $\mathrm{T}$ and ammonium molybdate [2-4]. Moreover some authors described spectrophotometric determination of phentothiazine as ion-pairs or complexes [5-7]. Other spectroscopic method used for phentothiazine derivatives determination is fluorimetry and luminescence [8-10]. Electrochemical methods [11-13] have been applied to the determination of phenothiazine drugs in pharmaceuticals and biological fluids. The most often in phenothiazine derivatives analysis liquid chromatography is used. This technique was applied for analysis of biological active substances in differ dosage forms [14-16] and biological fluids [17-21].

Many of papers described application of electromigration methods for determination of phenothiazines. Among these there is capillary electrophoresis (CE) [22-24]. Last time besides CE the capillary isotachophoresis was most often used in pharmaceutical analysis. Isotachophoresis is the separation technique for qualitative and quantitative analysis of ionic compounds, based on differences in their effective mobility in solution. This method was tested as a complementary method to HPLC for the determination of many pharmaceuticals [2527]. In our earlier papers capillary isotachophoresis was successfully applied for determination of neomycin trisulphate and metoprolol tartrate [28-30].

Because of we found only several papers [31-33] about application of capillary isotachophoresis for phenothiazine derivatives analysis we decided use this technique in our studies. In our paper we described the isotachophoretic method for determination of three phenothiazine derivatives: thioridazine hydrochloride (TDZ), promethazine hydrochloride (PMT) and chlorpromazine hydrochloride (CPM).
The linear calibration range was studied for eventual application of elaborated method to pharmaceutical preparations analysis. The obtained results were discussed with regards of accuracy and precision.

\section{Material and Methods}

\section{Chemical and reagents}

All used reagents were analytical grade. $\varepsilon$-aminocaproic acid (EACA), morpholinoethanosulphonic acid (MES), $\beta$-alanine and hydroxyethylcellulose (HEC) were purchased from Sigma and others reagents from Alchem, Torun (Poland). Thioridazine hydrochloride, promethazine hydrochloride, chlorpromazine hydrochloride and erythromycin were purchased from Sigma, (Germany), whereas the pharmaceutical preparations: Diphergan, Thioridazin and Fenactil were bought in local pharmacy. Demineralized water (conductivity below $0.05 \mu \mathrm{S}$ ) was obtained by HLP Smart 2000 purification system (Hydrolab, Poland) and was used for sample solution preparation.

\section{Isotachophoretic instrumentation and analysis conditions}

Isotachophoretic separations were performed using a Villa Labeco EA 100/101 isotachophoretic analyzer equipped with a conductivity detector. The PTFE pre-separation capillary $(90 \mathrm{~mm} \times 0.8 \mathrm{~mm}$ I.D. $)$ was connected with PTFE analytical capillary ( $160 \mathrm{~mm} \times 0.3 \mathrm{~m} \mathrm{I.D.})$. Samples were injected via a sample valve of $30 \mu \mathrm{L}$ fixed volume by internal sample loop. The isotachopherograms were evaluated with the PC software package supplied with analyser (KasComp, Slovakia).

Phenothiazines were analyzed applying three electrolytes systems: leading (LE) $-10 \mathrm{mM}$ sodium acetate $+0.08 \%$ hydroxethylocelulose (HEC)+acetic acid to $\mathrm{pH}=5.5$ and terminating (TE) $-10 \mathrm{mM}$ $\beta$-alanine (I); LE-10 mM morpholinoethanosulphonic acid (MES)+5 $\mathrm{mM}$ ammonium $(\mathrm{pH}=6.5)$ and $\mathrm{TE}-10 \mathrm{mM} \quad \varepsilon$-aminicaproic acid (EACA) $+0.08 \%$ HEC (II) and LE- $10 \mathrm{mM}$ sodium acetate $+0.08 \%$

*Corresponding author: Marzanna Kurzawa, Department of Chemistry, Nicolaus Copernicus University, 7 Gagarin str., 87-100 Toruń, Poland, Tel: +48-56-611-4369; Fax: +48-56-654-24-77; E-mail: jmk@umk.pl

Received Septemer 28, 2012; Accepted October 10, 2012; Published October 12,2012

Citation: Kurzawa M, Filipiak-Szok A, Jastrzebska A, Szłyk E (2012) Application of Capillary Isotachophoresis in Phenothiazines Determination. Pharmaceut Anal Acta 3:173. doi:10.4172/2153-2435.1000173

Copyright: (c) 2012 Kurzawa M, et al. This is an open-access article distributed under the terms of the Creative Commons Attribution License, which permits unrestricted use, distribution, and reproduction in any medium, provided the original author and source are credited. 
Citation: Kurzawa M, Filipiak-Szok A, Jastrzębska A, Szłyk E (2012) Application of Capillary Isotachophoresis in Phenothiazines Determination. Pharmaceut Anal Acta 3:173. doi:10.4172/2153-2435.1000173

HEC+acetic acid to $\mathrm{pH}=5.5$ and $\mathrm{TE}-5 \mathrm{mM}$ erythromycin (III). Previously, the system I was applied for neomycin analysis [29].

In this paper, new electrolyte systems (II and III) based on cationic mode separation was discussed. Leading electrolyte in system (III) was the same as in system (I), whereas as terminating ion we tested erythromycin, which characterized low effective mobility. Moreover, we proposed $10 \mathrm{mM}$ MES as leading ion with addition $5 \mathrm{mM}$ ammonium to $\mathrm{pH}=6.5$ in system (II). This $\mathrm{pH}$ value permitted optimizing phenothiazines stabilization and dissociation. It should be noted; these electrolytes composition was not used in phenothiazines analysis. The choice of electrolytes composition was discussed in details by Kurzawa [30].

The driving current of the pre-separation column was changed from $250 \mu \mathrm{A}$ to $150 \mu \mathrm{A}$ during the analysis in all causes. The determination conditions (HEC concentration, current intensity and $\mathrm{pH}$ ) were optimized by an analysis of phenothiazines standard solution.

Phenothiazines were identified using the relative step height (RSH) parameter which was calculated from the relation: $\mathrm{RSHX}=(\mathrm{HX}-\mathrm{HL})$ / (HT-HL), where HX is the zone height of analyzed substance, HL and HT is step height of leading and terminating ion, respectively [34].

\section{Preparation of standards}

Stock solutions of analyzed phenothiazines were prepared by dissolving appropriate amounts of the analyzed compounds in 100 $\mathrm{mL}$ demineralized water resulting concentration $100 \mathrm{mg} / \mathrm{L}$. Working standard solutions were prepared by dilution of stock solution obtaining concentration of each drug from 5.0 to $100 \mathrm{mg} / \mathrm{L}$.

\section{Preparation of pharmaceutical preparations}

Diphergan, Thioridazin and Fenactil solutions were prepared as follow: one, two and 3 tablets were crushed, dissolved in beaker with $150 \mathrm{ml}$ water and placed in ultrasonic bath. After sonification, the solutions were filtered and transferred to $1 \mathrm{~L}$ volumetric flask and made up to volume by water. The final concentrations of biological active compounds were $10.0 ; 20.0$ and $30.0 \mathrm{mg} / \mathrm{L}$.

\section{Method validation}

The elaborated method was validated in terms of linearity, withinday and between days precision, accuracy and limits of detection (LOD) and quantification (LOQ). Calibration curves were constructed as dependence of zone length on the concentration. The accuracy was tested by recovery value at three level of concentration. The withinday precisions were studied at three concentration levels by three time repetitions whereas the between-days precisions were evaluated by five consecutive days.

\section{Results and Discussion}

\section{RSH stability}

As was earlier described, the studied phenothiazines were characterized by RSH parameter which was calculated from the relation: $\mathrm{RSH}=(\mathrm{HX}-\mathrm{HL}) /(\mathrm{HT}-\mathrm{HL})$, where HX is the zone height of analyzed phenotiazines cation, HL and HT are step heights of the leading and terminating ion, respectively. The typical isotachopherograms for the studied phenothiazines are presented in figure 1 .

The mean RSH values of each studied pharmaceutical are presented in table 1.

The stability of RSH is one important parameter in isotachophoretic
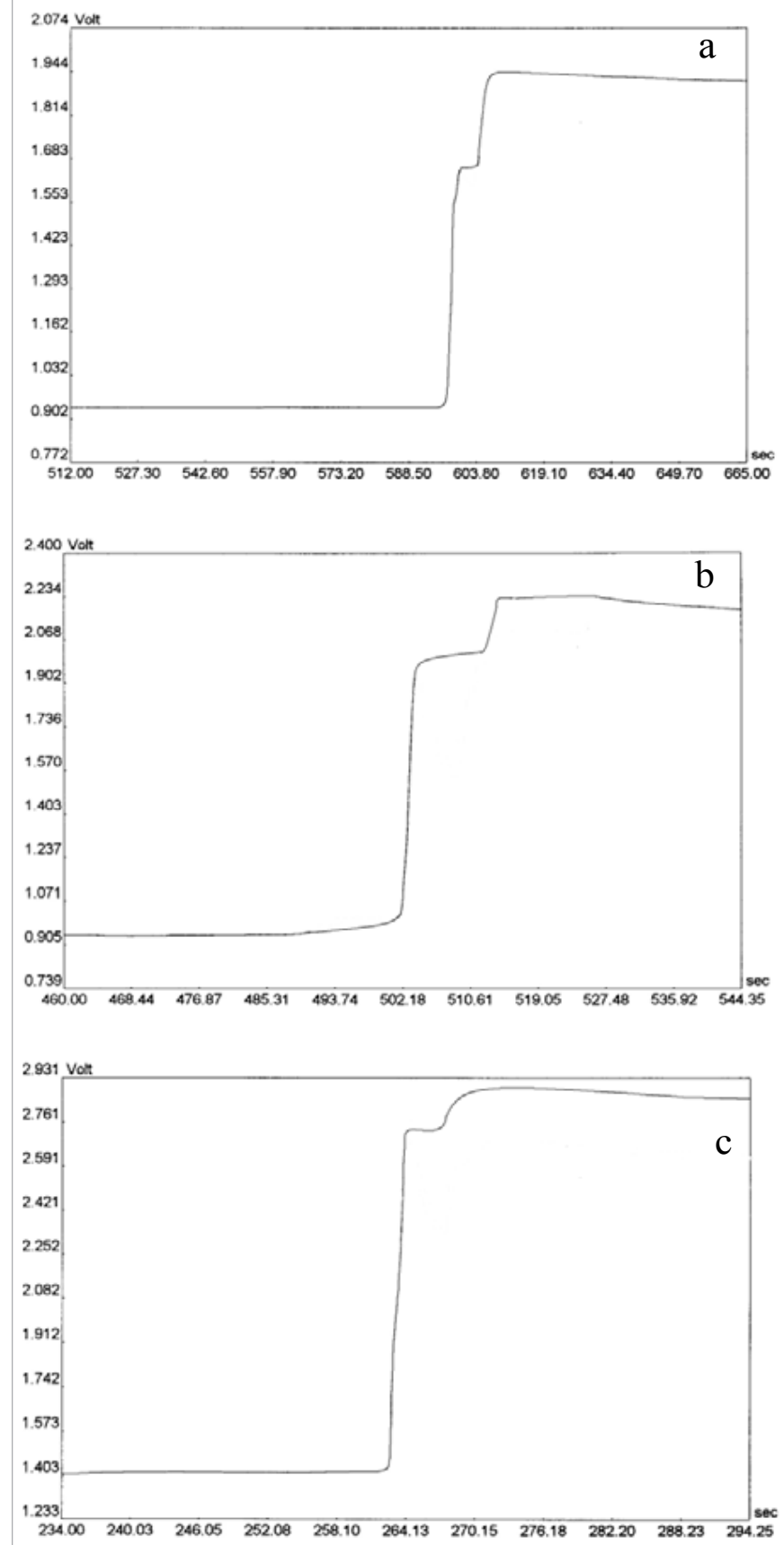

Figure 1: Isotachopherograms of: (a) promethazine (c=90 mg/L), (b) thioridazine (c=90 mg/L) and (c) chlorpromazine (c=70 mg/L) at I electrolyte system.

analysis. Relative standard deviations of RSH were also reasonable and amount below $1.6 \%$. The applied three electrolytes systems seem to be well adjusted to provide good performance of the method.

The analysis times were depending on the used electrolyte system and ranged from 5.33 to $13.55 \mathrm{~min}$.; from 8.78 to $12.20 \mathrm{~min}$. and from 4.60 to $11.90 \mathrm{~min}$. for promethazine, thioridazine and chlorpromazine, respectively.

\section{Calibration curves}

The calibration curves were constructed as the dependence 
Citation: Kurzawa M, Filipiak-Szok A, Jastrzębska A, Szłyk E (2012) Application of Capillary Isotachophoresis in Phenothiazines Determination. Pharmaceut Anal Acta 3:173. doi:10.4172/2153-2435.1000173

Page 3 of 4

\begin{tabular}{|c|c|c|c|}
\hline \multirow{2}{*}{ Electrolite system } & PMT & TDZ & CPM \\
\cline { 2 - 4 } & $\mathrm{RSH} \pm \mu$. & $\mathrm{RSH} \pm \mu$ & $\mathrm{RSH} \pm \mu$ \\
\hline I & $0.666 \pm 0.006$ & $0.608 \pm 0.012$ & $0.506 \pm 0.007$ \\
\hline II & $0.551 \pm 0.010$ & $0.594 \pm 0.010$ & $0.487 \pm 0.008$ \\
\hline III & $0.632 \pm 0.009$ & $0.612 \pm 0.006$ & $0.495 \pm 0.005$ \\
\hline
\end{tabular}

Where: $\mu$ - Confidence limit, $p=95 \%$;

Table 1: The mean RSH value of promethazine, thioridazine and chlorpromazine $(n=5)$.

\begin{tabular}{|c|c|c|c|c|}
\hline & Equation of calibration curve & $R^{2}$ & LOD, $\mathrm{mg} / \mathrm{L}$ & LOQ, $\mathrm{mg} / \mathrm{L}$ \\
\hline & System I & & & \\
\hline PMT & $\mathrm{y}=(0.1870 \pm 0.0005) \mathrm{x}+(0.300 \pm 0.002)$ & 0.9998 & 2.93 & 9.76 \\
\hline TD & $\mathrm{y}=(0.0480 \pm 0.0002) \mathrm{x}-(0.1760 \pm 0.0004)$ & 0.9990 & 2.34 & 7.82 \\
\hline CPM & $\mathrm{y}=(0.0980 \pm 0.0004) \mathrm{x}-(0.584 \pm 0.001)$ & 0.9990 & 1.93 & 6.45 \\
\hline & System II & & & \\
\hline PMT & $\mathrm{y}=(0.1080 \pm 0.0005) \mathrm{x}-(0.298 \pm 0.001)$ & 0.9998 & 2.70 & 9.01 \\
\hline TD & $\mathrm{y}=(0.1600 \pm 0.0007) \mathrm{x}-(1.267 \pm 0.001)$ & 0.9998 & 2.39 & 7.97 \\
\hline CPM & $\mathrm{y}=(0.1290 \pm 0.0006) \mathrm{x}+(0.925 \pm 0.001)$ & 0.9998 & 2.67 & 8.90 \\
\hline & System III & & & \\
\hline PMT & $\mathrm{y}=(0.1800 \pm 0.00030) \mathrm{x}-(1.048 \pm 0.006)$ & 0.9975 & 3.00 & 9.99 \\
\hline TD & $\mathrm{y}=(0.1650 \pm 0.0008) \mathrm{x}-(1.277 \pm 0.002)$ & 0.9998 & 2.69 & 8.98 \\
\hline CPM & $\mathrm{y}=(0.1570 \pm 0.0008) \mathrm{x}-(1.073 \pm 0.002)$ & 0.9998 & 2.60 & 8.66 \\
\hline
\end{tabular}

Table 2: The statistical parameters of calibration curves.

of zone length on the analyzed substances concentration. At each concentration levels five repetitions of measurements were made. The calibration curves are expressed as $y=\left(b \pm S_{b}\right) \cdot x+\left(a \pm S_{a}\right)$, where $S_{b}, S_{a}-$ standard deviations of slope and intercept. The statistical parameters of calibration curves are collected in table 2 .

Linear regression of elaborated procedure for each used electrolyte systems revealed good correlation. The calculated determination coefficients were from 0.9975 to 0.9998 . The determination coefficient values for analysed PHs were close to one what indicated satisfactory linearity between zone length and the concentration of studied pharmaceuticals.

The detection limit (LOD) of a method is the lowest analyte concentration that produces a response detectable above the noise level of the system, typically taken as three times the noise level. The quantitation limit (LOQ) is the lowest level of analyte that can be accurately measured, and it is often evaluated as ten times the noise level. In our studies we have evaluated both quantities according to the procedure of Miller and Miller [35]. Limit of detections were calculated from $\left(y+3 \cdot s_{\gamma / x}\right) / b$, where the calculated intercept of the calibration curve can be used as estimate of $y, s_{y / x}$ being the standard deviation in the $y$-direction of the calibration curve and $b$ being the slope of the calibration curve. The 10.s $/ b$ expression was used for estimation of the quantification limit. The LOQ is very important parameter, with respect to the potential applications of elaborated method. The obtained value suggested that our three electrolyte systems can be suitable for the analysis of pharmaceutical preparation containing analyzed phenothiazines (in all cases $\mathrm{LOQ}<10 \mathrm{mg} / \mathrm{L}$ ). Taking into account the fact that the lowest dose tested active substances in one tablet is $10 \mathrm{mg}$, they can be determined with sufficient accuracy and precision using the developed methods.

\section{Analysis of pharmaceutical preparations}

The elaborated methods of the phenothiazine derivatives determination were tested on the pharmaceutical preparations: Diphergan, Thioridazin and Fenactil. Each sample was analyzed 5 times at three concentration level $(10.0 ; 20.0$ and $30.0 \mathrm{mg} / \mathrm{L})$. The analyses were performed at the same conditions as calibration curve and results listed in table 3 .

The accuracy of the method was evaluated from recovery assays. In all cases the recovery values are close to $100 \%$ and fall within the scope required by British Pharmacopoeia [1].

Moreover, the relative standard deviation values are lower than 3\% what confirms good precision of the elaborated methods. The obtained results are similar as those obtained by Kubacak et al. [31]. Authors tested several electrolyte systems for promethazine determination and the best results were obtained for the following one: LE: $10 \mathrm{mmol} / \mathrm{L}$ of potassium acetate with acetic acid to $\mathrm{pH} 4.8$ and TE: $5 \mathrm{mmol} / \mathrm{L}$ of $\beta$-alanine with additive $0.2 \%$ methylhydroxyethylcellulose (m-HEC). The calibration graph was $r$ in the range of $40-200 \mathrm{mg} / \mathrm{L}$ with $\mathrm{R}^{2}=0.9992$. The RSD value was $1.12 \%$ and total analysis time was $6 \mathrm{~min}$. The recoveries of drug in pharmaceutical preparations were from $97.22 \%$ to 99.72\% depending on their therapeutic form.

The obtained results in respect to accuracy and precision can be compared with those obtained in our earlier papers [28-30] where we described determination of metoprolol tartrate and neomycin trisulfate with use of capillary isotachophoresis.

\section{Conclusion}

The developed isotachophoretic method for the determination of promethazine, thioridazine and chlorpromazine is precise, accurate, reproducible and relatively fast. Due to no consumption of organic

\begin{tabular}{|c|c|c|c|c|}
\hline pharmaceuticals & $\mathrm{C}_{\mathrm{det}} \pm \mu \mathrm{mg} / \mathrm{L}$ & Recovery, \% & $\mathrm{RSD}_{\text {intra-day }} \%$ & $\mathrm{RSD}_{\text {inter-days }} \%$ \\
\hline \multicolumn{5}{|c|}{ System I } \\
\hline \multirow{3}{*}{ Diphergan } & $10.04 \pm 0.05$ & 100.4 & 0.52 & 1.42 \\
\hline & $20.07 \pm 0.32$ & 100.3 & 1.28 & 1.32 \\
\hline & $29.98 \pm 0.13$ & 99.93 & 0.72 & 0.95 \\
\hline \multirow[t]{3}{*}{ Thioridazin } & $10.02 \pm 0.13$ & 100.2 & 1.15 & 1.11 \\
\hline & $19.95 \pm 0.10$ & 99.75 & 0.67 & 0.83 \\
\hline & $29.93 \pm 0.12$ & 99.77 & 0.34 & 0.56 \\
\hline \multirow[t]{4}{*}{ Fenactil } & $9.91 \pm 0.05$ & 99.10 & 0.74 & 0.98 \\
\hline & $19.89 \pm 0.08$ & 99.45 & 0.69 & 0.57 \\
\hline & $29.94 \pm 0.14$ & 99.80 & 0.53 & 0.43 \\
\hline & \multicolumn{4}{|c|}{ System II } \\
\hline \multirow[t]{3}{*}{ Diphergan } & $10.12 \pm 0.08$ & 101.2 & 0.58 & 0.68 \\
\hline & $20.07 \pm 0.09$ & 100.3 & 0.51 & 0.49 \\
\hline & $30.02 \pm 0.16$ & 100.1 & 0.49 & 0.75 \\
\hline \multirow[t]{3}{*}{ Thioridazin } & $10.13 \pm 0.07$ & 101.3 & 0.67 & 0.92 \\
\hline & $20.17 \pm 0.07$ & 100.8 & 0.38 & 0.67 \\
\hline & $30.20 \pm 0.10$ & 100.7 & 0.34 & 0.36 \\
\hline \multirow[t]{4}{*}{ Fenactil } & $10.10 \pm 0.05$ & 101.0 & 0.52 & 0.46 \\
\hline & $20.16 \pm 0.08$ & 100.8 & 0.73 & 0.95 \\
\hline & $30.22 \pm 0.07$ & 100.7 & & \\
\hline & \multicolumn{4}{|c|}{ System III } \\
\hline \multirow[t]{3}{*}{ Diphergan } & $9.87 \pm 0.07$ & 98.70 & 0.68 & 0.79 \\
\hline & $19.68 \pm 0.13$ & 98.40 & 0.70 & 0.82 \\
\hline & $29.58 \pm 0.13$ & 98.60 & 0.46 & 0.44 \\
\hline \multirow[t]{3}{*}{ Thioridazin } & $9.85 \pm 0.10$ & 98.50 & 0.98 & 0.92 \\
\hline & $19.66 \pm 0.15$ & 98.30 & 0.87 & 0.32 \\
\hline & $29.60 \pm 0.10$ & 98.67 & 0.72 & 0.61 \\
\hline \multirow[t]{3}{*}{ Fenactil } & $9.65 \pm 0.20$ & 96.50 & 1.56 & 1.24 \\
\hline & $19.56 \pm 0.22$ & 97.80 & 0.94 & 1.04 \\
\hline & $29.65 \pm 0.32$ & 98.83 & 0.94 & 0.99 \\
\hline
\end{tabular}

Where: $\mu$ - Confidence limit, $p=95 \%$; RSD - relative standard deviation.

Table 3: Determination of active substances in pharmaceuticals. 
Citation: Kurzawa M, Filipiak-Szok A, Jastrzębska A, Szłyk E (2012) Application of Capillary Isotachophoresis in Phenothiazines Determination. Pharmaceut Anal Acta 3:173. doi:10.4172/2153-2435.1000173

solvents and low consumption of electrolytes it is environmental friendly method. The obtained results clearly indicated that the method may be well suited for the routine pharmaceutical preparation analysis and can as an alternative to the commonly used titrimetric and chromatographic methods.

\section{References}

1. British Pharamcopoeia 5 electronic edition

2. Basavaiah $K(2003)$ A sensitive spectrophotometric method for the assay of three phenothiazine neuroleptics using periodate and variamine blue. Act Cien Ind Chem 29: 285-288.

3. Basavaiah K, Manjunatha SJ (2002) Titrimetric and Spectrophotometric Determinations of Some Phenothiazine Psychotropics Using Chloramine-T. Turk J Chem 26: 551-558.

4. Basavaiah K, Manjunatha SJ (2001) A Highly Sensitive Spectrophotometric method for the determination of some phenothiazine antipsychotics using chloramine-T and indigo carmine. Anal Sci 17: 963-967.

5. Basavaiah K (2004) Determination of some psychotropic phenothiazine drugs by charge-transfer complexation reaction with chloranilic acid. Farmaco 59: 315-321.

6. Basavaiah K, Krishnamurthy G (1998) Extractive spectrophotometric determination of some phenothiazine derivatives in pharmaceutical preparations. Talanta 46: 665-670.

7. Farhadia K, Savojbolaghia AK, Maleki R (2003) Study of reactions of triiodide and alizarin red $s$ with some important phenothiazines. Development of an indirect titrimetric and a spectrophotometric method for the assay of phenothiazine derivatives. J Chin Chem Soc 50: 153-159.

8. Laassis B, Aaron JJ, Mahedero MC (1994) Fluorimetric determination of phenothiazine derivatives by photooxidation in a flow-injection system. Talanta 41: $1985-1989$.

9. Zakhari NA, Rizk M, Walash MI, Ibrahim F (1985) Fluorimetric determination of certain phenothiazine derivatives using eosin. Anal Let 18: 1405-1417.

10. Laassis B, Maafi M, Aaron JJ, Mahedero MC (1997) Fluorimetric and photochemically induced fluorimetric determination of ethopropazine levomepromazine, thioproperazine and trifluoperazine. Anal Let 30: 1541-1554.

11. Ni Y, Wang L, Kokot S (2001) Voltammetric determination of chlorpromazine hydrochloride and promethazine hydrochloride with the use of multivariate calibration. Anal Chim Acta 439: 159-168.

12. Belal F, El-Ashry SM, Shehata IM, El-Sherbeny MA, El-Sherbeny DT (2000) Differential-pulse polarographic determination of some n-substituted phenothiazine derivatives through treatment with nitrous acid. Mikrochim Acta 135: 147-154.

13. Zhang ZQ, Chen ZG, Yang ZG, Zhang H (1996) Adsorptive voltammetric determination of chlorpromazine in the presence of Triton X-100. Microchem J 53: 282-289.

14. Mehta AC (1981) High-performance liquid chromatographic determination of chlorpromazine and thioridazine hydrochlorides in pharmaceutical formulations. Analyst 106: 1119-1122.

15. Takahashi D M (1980) Rapid determination of chlorpromazine hydrochloride and two oxidation products in various pharmaceutical samples using highperformance liquid chromatography and fluorescence detection. J Pharm Sci 69: 184-187

16. Karpinska J, Starczewska B (2002) Simultaneous LC determination of some antidepressants combined with neuroleptics. J Pharm Biomed Anal 29: 519525 .

17. Pistos C, Stewart J T (2003) Direct injection HPLC method for the determination of selected phenothiazines in plasma using a Hisep column. Biomed Chromatogr 17: 465-470.

18. Tanaka E, Nakamura T, Terada M, Shinozuka T, Hashimoto C, et al. (2007) Simple and simultaneous determination for 12 phenothiazines in human serum by reversed-phase high-performance liquid chromatography. J Chromatogr B Anal Technol Biomed Life Sci 854: 116-120.

19. Wallace JE, Shimek EL, Stavchansky S, Steven C, Harris SC (1981)
Determination of promethazine and other phenothiazine compounds by liquid chromatography with electrochemical detection. Anal Chem 53: 960-962.

20. Horst PG , Foudraine NA, Cuypers G, van Dijk EA, Oldenhof NJ (2003) Simultaneous determination of levomepromazine, midazolam and their majo metabolites in human plasma by reversed-phase liquid chromatography. Chromatogr B Anal Technol Biomed Life Sci 791: 389-398.

21. Marum A, Kumazawa T, Lee XP, Fujimaki K, Kuriki A, et al. (2005) Analysis of phenothiazines in human body fluids using disk solid-phase extraction and liquid chromatography. J AOAC Int 88: 1655-1662.

22. Lin CE, Liao W S, Chen KH, Lin WY (2003) Enantioseparation of phenothiazines in cyclodextrin-modified capillary zone electrophoresis: reversal of migration order. Electrophoresis 24: 3139-3146.

23. Chen KH, Lin CE, Liao WS, Lin WY, Hsiao YY (2002) Separation and migration behavior of structurally related phenothiazines in cyclodextrin-modified capillary zone electrophoresis. J Chromatogr A 979: 399-408.

24. Muijselaar PGHM, Claessens HA, Cramers CA (1996) Determination of structurally related phenothiazines by capillary zone electrophoresis and micellar electrokinetic chromatography. J Chromatogr A 735: 395-402.

25. Pospisilova M, Polasek M, Jokl V (2001) Determination of ambroxol or bromhexine in pharmaceuticals by capillary isotachophoresis. J Pharm Biomed Anal 24: 421-428.

26. Pospisilova M, Polasek M, Jokl V (1998) Determination of tramadol in various dosage forms by capillary isotachophoresis. J Pharm Biomed Anal 18: 777-783.

27. Polasek M, Pospısilova M, Urbanek M (2000) Capillary isotachophoretic determination of flufenamic, mefenamic, niflumic and tolfenamic acid in pharmaceuticals. J Pharm Biome Anal 23: 135-142.

28. Kurzawa M, Jastrzebska A, Szłyk E (2005) Indirect determination of neomycin trisulphate as sulphates by column coupling capillary isotachophoresis. Acta Pol Pharm 62: 163-169.

29. Kurzawa M, Jastrzębska A, Szłyk E (2009) Application of isotachophoretic and conductometric methods for neomycin trisulphate determination. Chem Pap 63: $255-260$

30. Kurzawa M (2010) Determination of metoprolol tartrate by capillary isotachophoresis. Chem Pap 64: 294-300.

31. Kubacak P, Mikus P Valaskova I, Havranek E (2005) Determination of promethazine hydrochloride in pharmaceuticals by capillary isotachophoresis. Methods find exp clin pharmacol 27: 529-532.

32. Jelinek I, Dohnal J, Snopek J, Smolkova-Keulemansowa E (1991) Use of cyclodextrins in isotachophoresis: VII. Resolution of structurally related and chiral phenothiazines. J Chromatogr A 464: 139- 147.

33. Snopek J, Jelinek I, Smolkova-Keulemansowa E (1992) Chiral separation by analytical electromigration methods. J Chromatogr A 609: 1-17

34. Everaerts FM. Beckers JL, Verheggen TPEM (1976) Isotachophoresis, Theory, Instrumentation and Applications. (Eds.), Elsevier Scientific Publishing Company, Amsterdam.

35. Miller JN, Miller JC (2000) Statistical and Chemometrics for Analytica Chemistry. Pearson Education Limited, England. 